The $B D J$ News section accepts items that include general news, latest research and diary events that interest our readers. Press releases or articles may be edited, and should include a colour photograph if possible. Please direct your correspondence to the News Editor, Arveen Bajaj at the BDJ, The Macmillan Building, 4 Crinan Street, London N1 9XW or by email to bdj@bda.org

\section{New Dental School appoints inaugural Dean}

The Peninsula Dental School, the first new Dental School in the UK for over 40 years, has appointed Professor Elizabeth Kay as inaugural Dean. Professor Kay is Professor of Dental Health Services Research at the School of Dentistry, University of Manchester.

The Peninsula Dental School is a joint school of the Universities of Exeter and Plymouth and works in close partnership with the NHS in Devon and Cornwall. It is a new initiative formed after a successful bid to Government, designed to take a fresh approach to the teaching and development of prospective dentists. It aims to ensure its graduates are best prepared to rise to the oral health challenges of the future. Professor Kay said, "The demands on today's dental professionals are extremely broad and as Dean of the School, the post represents an opportunity to put in place a programme which will be radical, reflect modern approaches to teaching and equip practitioners with the skills and abilities to adapt to rapidly changing professional roles."

The School will welcome its first group of students in September 2007 to the Bachelor of Dental Surgery (BDS) degree programme. The degree is a four-year full-time programme awarded jointly through the Universities of Exeter and Plymouth.

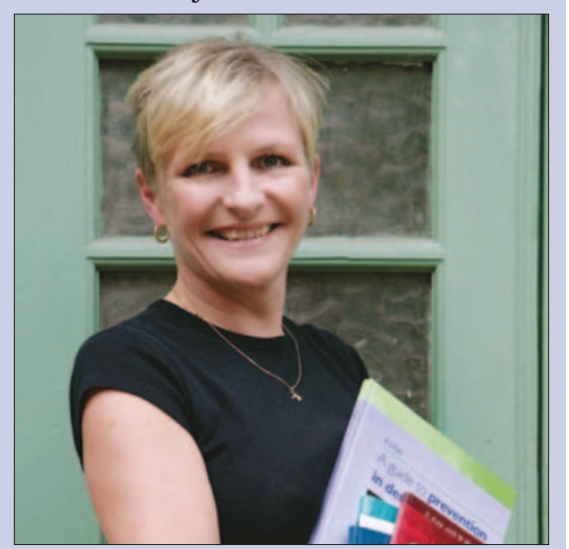

\title{
First child protection guide for dentists launched
}

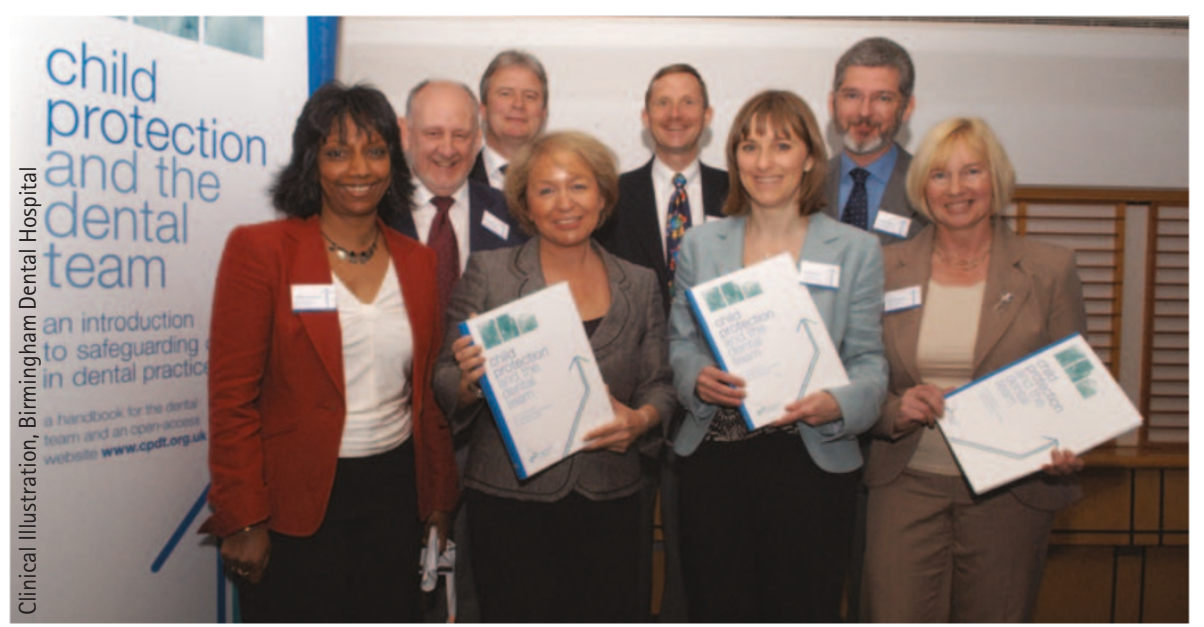

The first official guide to the dental team's role in child protection was recently launched by health minister Rosie Winterton, outlining their duties in the wake of the Victoria Climbié tragedy. Child Protection and the Dental Team was commissioned and funded by the Department of Health, and follows work by paediatric dentists to explore how they should meet the challenges set by Lord Laming's inquiry into the death of eight-year-old Victoria Climbié, following a year of abuse. The inquiry criticised health professionals for missing numerous opportunities to protect her. The new guide gives practical advice for the whole dental team on spotting the signs of abuse ranging from physical injury to changes in behaviour and interaction with parents. It then gives guidance on what to do if you suspect a child is suffering abuse. It also provides practical suggestions to help dental teams safeguard children, including advice on how to find out about local sources of help and further training.

NHS dental practices in England will receive a copy of the guidelines, accompanied by a letter from Barry Cockcroft, Acting Chief Dental Officer, reminding them of the responsibilities placed on all health care professionals to work together to safeguard children. Health minister Rosie Winterton said at the launch, "All health care professionals will, on occasions, come across children at risk of neglect and abuse. It is therefore vitally important that all members of the dental team are aware of the best way to recognise and help these children. Our experience of child protection work shows that safeguarding and promoting the welfare of children depends on effective joint working between agencies and professionals. This guide will enable members of the dental team to refresh their skills and knowledge in this vitally important area. "The handbook was developed by a multidisciplinary expert group, working in association with the Committee of Postgraduate Dental Deans and Directors, and is backed up by an open-access website www.cpdt.org.uk. Pictured above, Health minister Rosie Winterton with members of the expert group who developed the guide.

\section{Teeth needed for research project}

A third year student from Durham University needs help from dentists in Scotland, London and the Greater Manchester area to facilitate her research project as part of her BSc in Archaeology.

Keira Hope-Thompson is investigating the possible link between root transparency and age, which could enable age determination of adult skeletal remains to be performed much more accurately. Currently age determination of human skeletal remains can be performed with relative ease and accuracy for immature subjects via the accurate sequence of tooth eruption, but for adults it is much more difficult and unpredictable.

Keira needs to collect teeth from Scotland, London and the Greater Manchester area and compare them with known archaeological samples. Anyone interested in becoming involved in this research project should telephone Keira Hope-Thompson on 07813172485 or email keira@endodirect. co.uk for further information. 


\section{DIARY}

June

112th Meeting of the American Dental Society of Europe

Venue: Dubrovnik, Croatia

Date: 27-30 June 2006

Tel: 01413310088

www.adse.co.uk

84th General Session \& Exhibition of the International Association for Dental Research

Venue: Brisbane, Australia

Date: 28 June-1 July 2006

www.dentalresearch.org/meetings/brisbane/ index.html

July

82nd Congress of the European Orthodontic Society

Venue: Hofburg Congress Center, Vienna, Austria

Date: 4-8 July 2006

Tel: $(+43 / 1) 53116-38$

Fax: (+43/1) $53116-61$

Email: azmedinfo@media.co.at

\section{September}

The British Society of Paediatric Dentistry

Annual Scientific Conference

'The Art \& the Science'

Venue: The Hilton, Leeds City

Date: 12-15 September 2006

www.bspd.co.uk/conf-2006.html

European Society for Oral Laser Applications/ Hellenic Society for Oral Laser Applications 1st Mediterranean Laser Congress

Venue: Hilton Hotel Rhodes Resort, Greece

Date: 21-23 September 2006

Email: esola2006@medacad.org

www.esola.at

FDI Annual World Dental Congress

Venue: Shenzhen, China

Date: 22-25 September 2006

Email:congress@fdiworldental.org

www.fdiworldental.org

\section{November}

British Academy of Cosmetic Dentistry's (BACD)

2nd Annual Conference

Venue: Britannia International Hotel,

London

Date: 16-18 November 2006

Email:info@bacd.com

www.bacd.com

\section{DCP register open this Summer}

The date for opening the Dental Care Professional (DCP) register has been set for 31 July 2006, by the General Dental Council. Entry to the DCP register will be on the basis of training and qualifications recognised and regulated by the GDC. For a period of two years from the opening of the Register, some DCPs who do not have recognised qualifications will be able to register on the basis of their experience.

The titles dental hygienist, dental therapist, dental nurse, dental technician, clinical dental technician, and orthodontic therapist will be reserved by law for those DCPs who become registered and DCPs will be able to practise dentistry to the extent taught during their training. All DCPs will be responsible to the GDC for practising within the limits of their competence and on registration will be subject to the GDC's guidance on individual and team responsibilities.

DCP educational curricula will set out the knowledge, skills and attitudes that a DCP must have on first registration and they will be able to expand their range of skills through recognised training and experience. The Council says that its ability to meet this opening date is subject to Council approving the statutory rules, which will then need to be approved by the Privy Council in July.

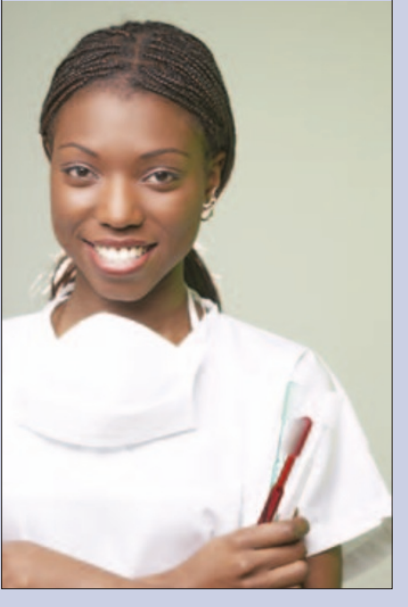

\section{Dentist's bid to boost donor numbers}

A former dentist who received a heart transplant is urging dental practices to display organ donor leaflets, and help save lives. Father of two Rob Hodgkiss, 38, says that dentists could make a big difference to donor numbers by displaying the leaflets and giving their patients the opportunity to join the NHS Organ Donor Register. He said, "My life was saved thanks to the kindness of a donor, but not everyone is so lucky. There's a desperate shortage of organ donors and it's vital that more people are given the opportunity to find out about donation and to join the register if they wish. "Dentists, like GPs, are ideally placed to help raise awareness of organ donation by displaying UK Transplant's leaflets in their practice waiting rooms and reception areas."

Rob practiced in the North-East before a rare heart condition led to a transplant in 1996. His operation was a success but the transplant medication left him with a slight hand tremor and he was unable to continue in dentistry. He has now retrained as a physiotherapist and enjoys an active life. UK Transplant Managing and Transplant Director Chris Rudge is a former transplant surgeon. He said, "Dentists are in a unique position to help us offer patients the

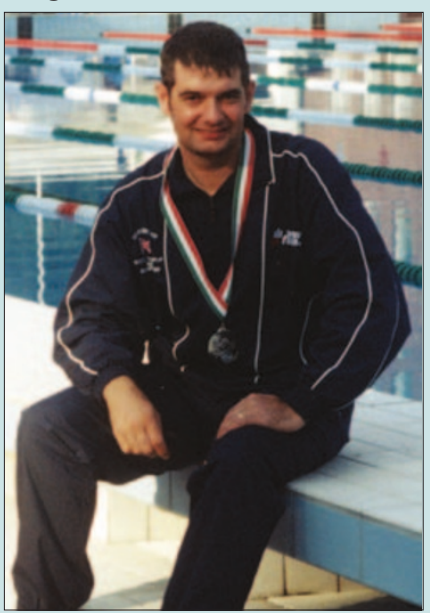
chance to join the register and are meeting public expectations in doing so. By displaying leaflets in their surgeries, dental practitioners are giving more patients the opportunity to join the NHS Organ Donor Register and, ultimately, save lives." According to UK Transplant, more than 8,000 people in the UK currently need a transplant to save or dramatically improve their lives but fewer than 3,000 transplants can be performed due to the shortage of organs. About 400 people die every year while waiting for a suitable organ to become available. Leaflets, dispensers and posters are available to order free from the NHS Organ Donor Line on 08456060400 .

Rob Hodgkiss at the British Transplant Games, 2003 


\section{Tension headache may be TMJD}

People whose recurrent headaches have been diagnosed as tension-related actually may be suffering from temporomandibular muscle and joint disorder, (TMJD) a study claims.

The study, headed by a researcher from the University at Buffalo's School of Dental Medicine showed that examiners could replicate tension-headache symptoms in 82 per cent of subjects by performing the clinical examination of the temporalis muscle, which is involved in TMJD.

The study involved 583 participants, 82.3 per cent female and 17.7 per cent male who were recruited as cases from the community based on the presence of symptoms clearly associated with TMJD. Of the participants, 152 were diagnosed with tension-type headache by the examiners. The study compared the diagnostic procedures for pain and the reproduction of pain versus headache during the clinical examination. Procedures included a range of functional and orthopedic tests and standard pain sensitivity to pressure applied to the muscles associated with headache. The types of headaches considered included sub-clinical headaches, tension-type headaches and headaches exhibiting more symptoms than are accepted for tension-type headaches, such as the mixed headache, migraine or migraine-type headaches.

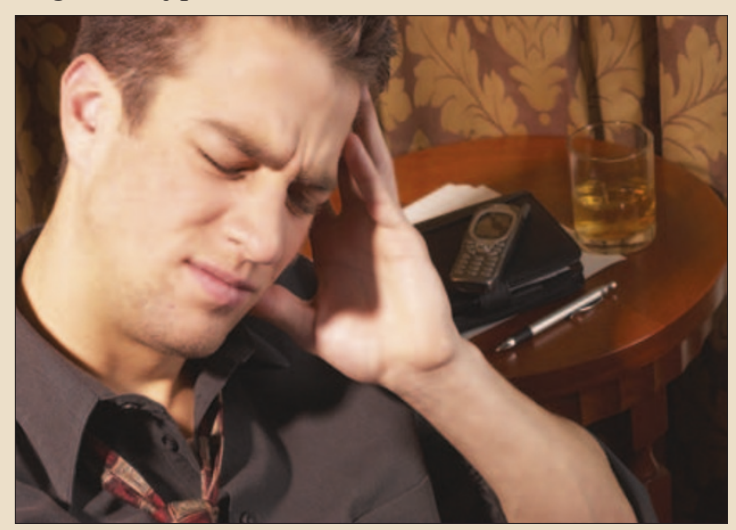

Richard Ohrbach, Associate Professor in the Department of Oral Diagnostic Sciences, presented the study results at the American Association of Dental Research meeting held recently in Orlando. "Because the headache is so incredibly common, it is often regarded as inevitable, and if sufferers label the pain as a headache, they may not seek help," said Professor Ohrbach. "Or if they do seek help, the label of headache typically will propel the individual to a physician or neurologist for consultation.

Knowledge about the intersection between jaw pain and headache is not well established, and consequently, jaw pain may be ignored in the differential diagnosis." The current study is part of an \$8 million project to establish valid and reliable TMJD diagnostic criteria. Results will advance the field of TMJD research and aid clinicians in their practices.

\section{Australia recognises UK dental nursing qualifications}

UK dental nursing qualifications will now be recognised in Australia, following negotiations between the British Association of Dental Nurses (BADN) and the Dental Assistants Education Council of Australia (DAECA).

Holders of the National Certificate or the S/NVQ 3 Oral Healthcare: Dental Nursing wishing to work in Australia will be able to apply for the DAECA certification and badge (cost approximately £30) by supplying DAECA with a copy of their qualification certificate and a letter confirming their BADN membership.The Federal and State Branches of the Australian Dental Association and the Office of Overseas Skills Recognition have been informed that both the National Certificate and the S/NVQ 3 are now recognized by the DAECA.

BADN President Michelle Brindley said "Many young dental nurses decide to broaden their horizons by traveling and working abroad, and Australia - with its scheme for the under 30s - is a popular destination. BADN are now hoping to reach similar agreements with other countries."

Dental nurses planning to work in Australia and wishing to obtain DAECE recognition of their UK qualification should contact BADN on 01253338360 , admin@badn.org.uk or visit the BADN website www.badn.org.uk for more details.

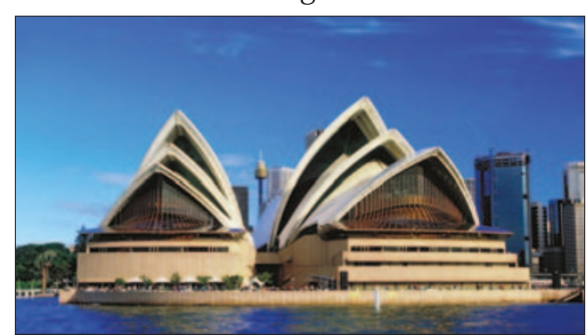




\section{New scheme launched}

The Faculty of General Dental Practice (UK) (FGDP(UK)) and the Department of Health have announced the publication of detailed competency frameworks for Dentists with Special Interests (DwSIs).

The frameworks are intended for use by dentists and primary care trusts (PCTs) and set out competencies for the scope of treatment that can be undertaken by DwSIs. Frameworks are currently available in the areas of minor oral surgery, orthodontics, periodontics and endodontics, with additional areas to follow.

The DwSI scheme provides PCTs with the flexibility to contract with dentists who have developed special interests in addition to their generalist role. This will help widen the choice available to patients in terms of the nature and locality of NHS dental care provided.

Dentists wishing to be accredited as a DwSI will be required by their PCT to demonstrate knowledge, skills and experience in their special interest area against the competency frameworks.

In addition to the frameworks, a Step-by-step guide to setting up a DwSI service takes PCTs through the process of assessing whether the commissioning of dental services from a DwSI would be appropriate, how such practitioners should be accredited and how a service might operate.

Nationally, the FGDP(UK) is able to advise on appropriate training to meet the generalist and special interest competencies, and provide help through its Career Pathway on demonstrating competencies through the production of an evidencebased portfolio.

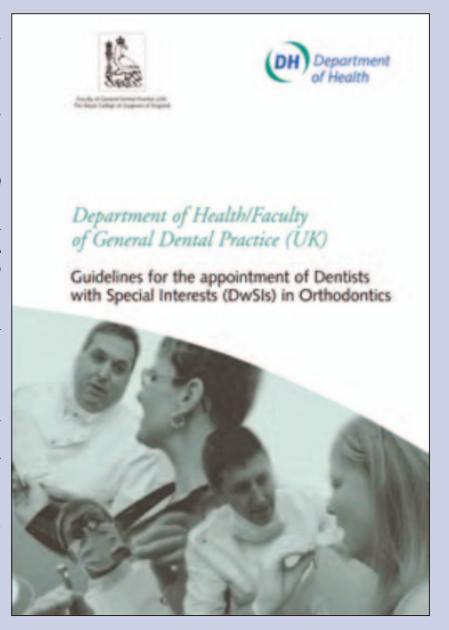

\section{Manchester launches new dentistry programme}

The University of Manchester's School of Dentistry is to launch the Manchester Dental Programme this September with the aim of creating dentists who can rise to the challenges of the ever-changing demands of the profession.

The Bachelor of Dental Surgery (BDS) programme has been specifically designed to 'break down the barriers' between dentists' pre-clinical and clinical experience, with basic scientific and clinical knowledge and skills being taught in parallel from year one along with transferable skills like ICT, communication and professional conduct.

Professor of Dental Education at the School, Iain Mackie said, "We are bringing clinical dentistry forward into the first year of the course and getting students to start seeing patients much earlier; running theory alongside clinical practice right through the fiveyears. So when students learn the theory they will also be reinforcing it with clinical practice from day one." The programme has the sub-title 'an integrated, enquiry-based curriculum, and an enquiry-based learning approach spans its five year duration. Senior Lecturer in Orthodontics Dr David Bearn, who is leading the introduction of the programme, said, "There is no doubt we all learn best through enquiry and problem-solving. The Manchester Dental Programme has been designed to incorporate these aspects throughout, helping students get a better understanding of dentistry and how its scientific basis supports clinical practice." Finally the programme places a strong emphasis on teamwork, reflecting the emphasis on this in the working structure of the profession. Each student will belong to a team made up of students from each of the five years of the programme, plus a BSc Oral Health Sciences student and a BSc Dental Technology student at the

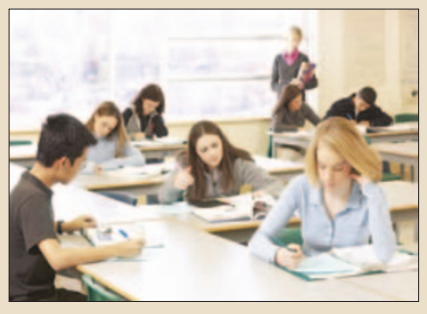
neighbouring Manchester Metropolitan University. Professor Mackie continued, "These teams will reflect the full team in dental practice, as well as helping students develop the skills highlighted in the recent General Dental Council publication 'Principles of Dental Team Working. For example, the final year student within each team will need to take on a leadership role, which will be invaluable experience when they go into practice." 